\title{
Eyelid Capillary Hemangioma
}

National Cancer Institute

\section{Source}

National Cancer Institute. Eyelid Capillary Hemangioma. NCI Thesaurus. Code C4357.

A capillary hemangioma arising from the eyelid. 